\title{
Effects of stress on economic decision-making: \\ Evidence from laboratory experiments
}

\author{
Liam Delaney \\ Günther Fink \\ Colm Harmon
}

Stirling Economics Discussion Paper 2014-02

March 2014

Online at:

http://www.stir.ac.uk/management/research/economics/workingpapers/ 


\title{
EFFECTS OF STRESS ON ECONOMIC DECISION-MAKING: EVIDENCE FROM LABORATORY EXPERIMENTS
}

\author{
Liam Delaney ${ }^{\mathrm{a}, \mathrm{b}^{*}}$ \\ Günther Fink ${ }^{\mathrm{c}}$ \\ Colm Harmon ${ }^{\text {d, e }}$
}

22 $^{\text {nd }}$ March 2014

${ }^{a}$ Stirling Management School, University of Stirling, United Kingdom.

${ }^{\mathrm{b}}$ Visiting Professor of Economics, University College Dublin, Ireland.

${ }^{c}$ Department of Global Health and Population, Harvard School of Public Health, United States.

${ }^{\mathrm{d}}$ School of Economics, University of Sydney, Australia.

${ }^{\mathrm{e}}$ Research Fellow, IZA

*Corresponding author

\section{Author Contact Details:}

Liam Delaney: Address: University of Stirling, Stirling, FK9 4LA, United Kingdom. Email: liam.delaney@stir.ac.uk. Telephone: 00447933422654

Günther Fink: Address: Room 1110, Building 1, Department of Global Health and Population, 665 Huntington Avenue, Boston, Massachusetts 02115, United States.

E-mail: gfink@hsph.harvard.edu. Telephone :+617-495-3708

Colm Harmon: Address: School of Economics, H04 - Merewether Building, The University of Sydney. E-mail: colm.harmon@sydney.edu.au. Telephone: +61 293515625 


\begin{abstract}
The ways in which preferences respond to the varying stress of economic environments is a key question for behavioral economics and public policy. We conducted a laboratory experiment to investigate the effects of stress on financial decision making among individuals aged 50 and older. Using the cold pressor task as a physiological stressor, and a series of intelligence tests as cognitive stressors, we find that stress increases subjective discounting rates, has no effect on the degree of risk-aversion, and substantially lowers the effort individuals make to learn about financial decisions.
\end{abstract}

Keywords: stress, financial decisions, discounting, risk aversion, learning.

JEL Classification codes: D91; I310. 


\section{Introduction}

The assumption of stable preferences is crucial to the definition of rationality in traditional economic models. However, a large recent literature points to non-stationarity of preferences in several empirical settings (e.g. Camerer 2004). Understanding the extent and biological basis of such instability is a key task that benefits from a better understanding of the role of biological stress processes in generating fluctuations in preferences, valuation and choices. Many important economic outcomes are generated by choices made often in stressful and unfamiliar environments and it is questionable whether the preferences held by individuals when construing tradeoffs in these environments are identical to preferences held when thinking about such tradeoffs in the abstract. Examples include making life-changing decisions about debt in the environment of a financial institution, under perceived time pressure, and making decisions about job-offers in the context of welfare centers. Furthermore, many economic outcomes generate stress and it is possible that the stress generated by such outcomes yields decision-making patterns that are inconsistent with rational behaviour e.g. suboptimal debt resolution mechanisms and inefficient job search patterns (e.g. Krueger and Mueller 2010, 2012).

While a body of psychological literature exists examining the effect of stress on decision-making, this literature is still very incomplete in terms of application to important economic questions. In particular, we have very little understanding of how stress influences the types of preferences central to economic decision making and economic models. We also have almost no evidence at all of the economic significance of the effect of stress on preferences and whether these effects are substantial enough to merit a change in core models of economic decision-making and ultimately the design of major policy institutions such as welfare mechanisms and regulatory structures for financial marketing and bankruptcy resolution.

Our study investigates the effects of acute stress on financial decision-making, where subjects were invited to participate in two independent laboratory sessions. During both sessions, subjects were asked to respond to two blocks of financial decision tasks. After the first block, which lasted approximately 25 minutes, respondents were randomly assigned to one of three groups: a control group, who did not receive any stressor, a cognitive stressor group, 
and a physical stressor group. Respondents assigned to the cognitive stressor protocol were subjected to a series of IQ questions, designed to increase in difficulty such that all participants would fail the tasks eventually. Under the physical stressor protocol, subjects were asked to place both of their feet into ice-cold $\left(4^{\circ} \mathrm{C}, 40^{\circ} \mathrm{F}\right)$ water, a "cold pressor test” which is widely used in the medical literature and generally induces substantial increases in blood pressure as well as other sympathetic nervous system indicators (Wirch et al, 2006, Richardson et al., 2013). Appendix 1 illustrates the setup of the physical stressor. After being exposed to the stressor, individuals were asked to respond to a second set of financial questions similar to the questions asked prior to the stressor. We find that exposure to stress significantly increases the degree of discounting displayed by individuals, and leads to large reductions in the respondents' willingness to learn about investment options before making their final decision. On average, we find that stress increases monthly discounting rates by about one third, and reduces the average effort made to learn about risky decisions by about 20 percent. We also find that stress increases the degree of risk aversion - the observed differences in risk aversion were however not statistically significant.

This paper provides the first rigorous estimates of the effects of experimentally-induced stress on decision making in three formalized economic tasks: risk preference elicitation, time preference elicitation and search tasks. The paper is structured as follows. Section 2 examines previous literature on the topic of unstable time preferences. Section 3 describes the data and experimental methods used in the paper. Section 4 provides the results. Section 5 discusses the findings and concludes with recommendations for future research.

\section{Literature and rationale for experiments}

\subsection{Theoretical Background}

There is a long tradition in economics of assuming that preferences are consistent. However, several studies show that this is not the case and that preferences fluctuate depending on various situational factors. For example, the empirical validity of the assumption that time preferences are well-approximated by exponential discounting functions which imply consistent preferences has been questioned (e.g. Samuelson 1937; see Frederick et al 2002 for review). 
Furthermore, there have been intensive efforts to establish the extent and nature of individual differences in economic preferences. Most of this literature has focused on cognitive factors such as IQ and numeracy, executive functions such as working memory, and noncognitive traits such as impulsivity and sensitivity to reward (Shamosh et al., 2008; Shamosh \& Gray, 2008; Reynolds et al., 2006). While this literature generally assumes that the traits driving individuals' behavior are predetermined, evidence from lab-based experiments suggests that mood and emotional state can strongly affect individual decisions in the short run (see, e.g., Knapp and Clark, 1991).

One strand of this new literature, summarized in Laibson, Repetto and Tobacman (2007), measures discount rates using panel data on consumption, income, and savings over the lifecycle. More commonly, lab experiments have been used to elicit time preference with questions asking subjects to weigh immediate gains versus delayed rewards (reviewed in Ainslie, 1992 and Frederick, et al, 2002). A series of recent papers have also tried to link shortterm decision processes to differential limbic system activation of the brain (McClure et al, $2004 \&$ 2007). These studies find that short-term tradeoffs are generally processed in the emotion-focused subcortical limbic system, while long-term tradeoffs generally appear to be processed by the more cognitively orientated frontal-parietal system. While these studies have strengthened the links between individual decision processes and neuroscience, they fall short of explaining the large degree of heterogeneity observed across individuals when it comes to inter-temporal tradeoffs. A large literature has analyzed financial decision-making in laboratory settings in general, and the choices involved in trading immediate gains against delayed rewards in particular (reviewed in Ainslie, 1992 and Frederick, Loewenstein \& O’Donoghue, 2002). More importantly, the relative weighting of short- versus long-term benefits is critically affected by the physical and mental state of respondents, and strongly influenced by primary impulses such as hunger, thirst and sexual arousal.

\subsection{Stress and Economic Preferences}

One central aspect of an individual's mental state, and the focus of this study, is shortterm stress. Stress, which we shall define as state of strain or suspense, can be induced by a variety of physiological, social and cognitive factors. Physiologically, external stress factors trigger a state of alarm, generally associated with an increased production of adrenaline and 
cortisol, higher blood pressure and increased heart beat frequency. Acknowledging the effect of stress on economic preferences can provide a better understanding of both inconsistent preferences and heterogeneity of preferences related to financial decision making.

Previous research has shown the importance of stress in explaining financial decision making. Stress levels have been shown to predict both inconsistencies and heterogeneity in economically-relevant situations. A recent study investigated the effect of a cognitive stressor on decision making (Heereman \& Walla, 2011). Two experiments were conducted; the probability of an outcome was unknown in one experiment and known in another. Selfreported confidence in a decision was higher in stressed participants than controls when outcome probabilities were unknown. The opposite effect was found when outcome probabilities are known (stressed individuals reported lower confidence). Stress levels were confirmed through skin conductance measures.

Two studies have identified gender differences in financial decision-making when stressed. Preston, Buchanan, Stansfield, and Bechara (2007) report that female participants anticipating giving a speech (stressed condition) performed better than controls on the Iowa Gambling Task (IGT). Men in the stress condition performed worse than controls. While this study did not have sufficient power to perform a reliable gender analysis, these results were replicated in a subsequent study. Van den Bos, Harteveld, and Stoop (2009) found a significant difference between males and females on the Iowa Gambling Task (IGT) after stress was induced (Trier Social Stress Test; TSST). In male subjects, higher cortisol levels were related to poorer performance on the gambling task. A slight increase in cortisol levels improved performance in female participants, while a higher increase reduced performance. More recently Haushofer et al (2013) find no effects of stress on inter-temporal choice. Using a sample of male undergraduates in the University of Zurich, they find that hormonal reactivity to a Trier Stress task does not predict changes in time discounting. In general, they do not find differences in discounting related to the stressor.

Shamosh et al. (2008) investigated whether working memory might also determine delay-discounting ability but found no effect. Similarly, Porcelli and Delgado (2009) found that stress did not affect working memory performance. Porcelli and Delgado (2009) also describe the effect of acute stress on financial decision-making. They found a "reflection effect" under 
stressful conditions whereby conservative choices are more likely to be reported when making decisions related to profit and risky decisions reported when making "loss” choices. An observational study, which contributed ecological validity to the topic of stress and financial decision making, recorded cortisol and testosterone in male traders (Coates \& Herbert, 2008). Morning testosterone level predicted the subject's profitability that day, while cortisol levels rose with market volatility and variation in trading results. Reviews on the effect of stress on neurophysiology and the sympathetic nervous system have been published by Dickerson \& Kemeny (2004); Nater \& Rohleder (2009).

In this study, we use a laboratory experiment to investigate how cognitive and physiological stressors affect decision-making. In contrast to most laboratory experiments which focus either on a mixed or a student population, our focus is on individuals aged 50 and over. The focus on individuals of this age group is important for two reasons: firstly, it can be presumed that individuals in this age group will exhibit far larger variation in terms of lifestyles and day-to-day exposure to stress. Second, relatively little evidence regarding the general decision patterns among this age group is available, though many of the most important lifetime financial decisions regarding long-term health insurance, retirement saving and final retirement decisions are made by individuals in this age bracket. Another important aspect of our study is the use of well-known economic preference questions that allow us to benchmark the quantitative importance of the stress effects being examined.

The results of this project have implications both for economic theory and applied decision-making research. By integrating stress as a determinant of economic preferences, some intra-individual fluctuations and inter-individual heterogeneity of preferences, which are not consistent with traditional stress-free economic models, might be explained. Empirically, the research can contribute to a better understanding of many economic decisions made in arguably stressful situations.

\section{Sample Recruitment and Experiment Design}

\subsection{Sample and Recruitment}

As this study was particularly concerned with decision-making among older people, only participants aged 50 and older were eligible for the study. While some subjects were recruited 
from an existing subject pool maintained by the laboratory, few subjects over 50 were available, so that most recruitment was done through Craigslist (www.craiglist.com). Craigslist is an online 'bulletin board' of adverts. In terms of recruitment, this means that all subjects had subjects had to have access to the Internet and be able to reply to an ad by e-mail. Study participants were informed that the experiment would require them to answer questions on a computer. In order to exclude adverse reactions to stress, we excluded respondents with a history of heart attack or stroke, uncontrolled thyroid condition or thyroid surgery within the last 6 months, and respondents under treatment with anticoagulation medication. Given that one of the stressors involved being exposed to cold water we also excluded subjects with a known sensitivity of fingers or toes to exposure to cold diagnosed by a health professional (a syndrome known as Raynaud's phenomenon).

Our sample recruitment, inclusion restrictions, and the need for a multi-visit participation in the experiment, were likely to lead to a more educated, less economically active, sample. To provide a better sense of these differences, we compare the sample population with the US census population (US Census Bureau, 2011). Table 1 shows descriptive statistics for study participants and a comparison sample from the same (over 50s) population. The average study participant was 57 years old; the oldest study participant was 79 at the time of the lab session, while the youngest just 50. As the table shows, people from oneperson households were over-represented in the study - only $17 \%$ of participants were married compared to $63 \%$ in the overall population, and also a surprisingly large fraction (41.05\%) of the participants were never married, in contrast to the $7.38 \%$ of the U.S. population that has never been married. Additionally, the participants tended to be more educated than the U.S. average from the equivalent age groups - a gap that is statistically significant. For example, over $90 \%$ of study participants had some college or higher education, which is only true for $51 \%$ of the overall population in that age group. In contrast, the labor participation rate among the study population was lower, and a higher percentage of the study population belongs to the lowest income bracket used in the census (U.S. Census Bureau, 2011).

[TABLE 1 HERE] 


\subsection{Design}

The laboratory experiment was conducted at the Harvard Decision Science Laboratory. ${ }^{1}$ The laboratory features thirty-six cubicles equipped with networked PCs. Twelve of the cubicles, exclusively used for our study, also feature physiological measurement equipment, which includes three modules: an impedance cardiograph, a four-channel bio amplifier, and a fourchannel transducer module.

Eligible individuals were briefed at the laboratory facilities, and upon giving their consent, enrolled in the study for three days. On Day 1, individuals participated in a laboratory session, which lasted approximately one hour. The session was divided into two blocks of financial decisions, with a short-break in the middle, during which a randomly selected stressor was administered to the treatment groups as detailed below. Throughout the entire laboratory session, heart rates were monitored continuously through a Suunto heart rate belt worn around the chest. In addition, four measures of blood pressure, and two saliva-based cortisol measures were taken at various points throughout the laboratory study as two alternative measures of stress. On the second day of the study, participants were asked to continuously wear the heart rate belt in order to obtain an estimate of study participants' heart rate variability and range on a typical day. In addition, participants were asked to complete a short phone interview during which information about location and activities were collected. On Day 3, participants were asked to return to the laboratory for a second experimental session identical in structure (except for the stressor) to the session on Day 1.

During each laboratory session, study participants were randomly assigned to one of three stressor groups: no stressor (control), cognitive stressor, and physical stressor. The cognitive stressor was made up of a series of IQ test questions designed to make people fail. Subjects were exposed to three principal tasks: A color STROOP test (Jensen \& Rohwer, 1966), the Paced Auditory Serial Addition Test (PASAT) (Gronwall 1977) and a series of forward and backward digit span tests (Humstone (1919), Schroeder et al., 2012). In the cognitive stressor session, each task completed correctly was followed by a more challenging task, and once three tasks within a given task were failed, individuals moved on to the next task.

\footnotetext{
${ }^{1}$ See decisionlab.harvard.edu for details on facilities.
} 
In order to generate physical stress, study participants were asked to immerse both feet into a foot bath filled with ice-cold ( $4^{\circ}$ Celsius, $40^{\circ}$ Fahrenheit) water. This “cold-pressor” test is a cardiovascular test commonly performed to test vascular response and pulse excitability; the response to the cold water immersion triggers a physiological response, leading to a statistically significant increase in both heart rate and blood pressure as described in further detail below. $^{2}$ In total, 97 participants were enrolled in the study, with 93\% (90) successfully completing both laboratory sessions, for a total of 187 sessions. Table 2 outlines the key descriptive statistics for the study population (See Appendix 1 for Cold Stressor Task Pictures).

\section{[TABLE 2 HERE]}

\subsection{Measures}

The core objective of the study is to understand the effects of stress on decision making. We assess three commonly used measures of decision making: implicit discount rates, the degree of risk aversion, and willingness to invest in acquiring relevant information before making financial decisions.

\section{Time Discounting}

To measure time discounting, the study incorporated a set of inter-temporal choice questions developed by Kirby and Marakovic (1996). Each question prompts respondents to make a decision between a financial payoff "today" and a larger future payoff. The questions vary both the current payoff, the future payoff, and the time period the respondent has to wait to receive the future reward. In order to ensure truthful reporting to all financial trade-off questions, one choice question was randomly selected for payout at the end of the section, and subjects paid based on their decisions.

As outlined in Table 3, a total of 21 discounting questions were asked to subjects in each session - 11 prior to the stressor, and 10 after the stressor. The questions are relatively

\footnotetext{
${ }^{2}$ The cold pressor task is a widely used method for inducing laboratory discomfort and stress without placing the respondent at risk. Birnie and colleagues (2011) examined self-reports of the cold pressor task given by children. They distributed surveys to children (and their parents) who had participated in cold pressor tasks. All children indicated they were happy they had participated $(n=175)$, and while $33 \%$ of children identified the cold pressor task as the least enjoyable aspect of the research, average overall experience was rated highly (mean 8.37/10). $99 \%$ of parents said they would take part in a research study in the future and that they would recommend the experience to a friend $(n=194)$.
} 
straightforward, and simply ask people questions along the lines of "Would you rather have [.] dollars today, or [.] dollars in [.] days?” Implicit discounting rates varied widely, ranging between $1 \%$ (question 2) and $400 \%$ (question 8 ).

\section{[TABLE 3 HERE]}

\section{$\underline{\text { Risk Aversion }}$}

To measure risk aversion, the study presented each participant with a sequence of ten choices between two lotteries as proposed by Holt and Laury (2002). Each question confronts study participants with a choice between two lotteries. Both lotteries feature the same probabilities of the good and bad outcomes, respectively. The main difference is that one lottery comes with a significantly larger spread, i.e. a significantly larger difference between the good and the bad outcome; these differences in risk are paired with differences in net payouts, which can be positive or negative. The Holt and Laury questions are designed to allow both for risk-averse and risk-loving preferences. For example, in question number eight in Table 4, respondents are given the choice between one lottery paying US \$20 with 90 percent probability, and paying US \$30 with 10 percent probability, and another lottery paying US\$ 10 with 90 percent probability, and US $\$ 50$ with 10 percent probability. To any risk-neutral or risk averse individual, this choice is easy, since the risky lottery promised US \$7 more in expected terms; only respondents with preferences for risk will choose option B in this case.

\section{[TABLE 4 HERE]}

In order to estimate the level risk aversion displayed by study participants, we ranked choice sets with respect to the expected payouts in compensation for the additional risk undertaken in Table 5. As expected, the fraction of individuals choosing the more risky option increases with the magnitude of the reward for taking the risk. Quite remarkably, even with a marginally negative reward (lower expected payoff with higher risk - question 4) 20\% of individuals choose the more risky version; the fraction declines to $8 \%$ once the expected value difference becomes larger.

\section{[TABLE 5 HERE]}

Willingness to Learn 
To measure willingness to learn, we implemented a slightly modified version of the “experience-sampling” task developed by Erev et al (2010) and Hertwig et al (2004). In this game, individuals have to make a choice between a save payout and a lottery. Rather than telling participants the payouts and respective probabilities, participants face uncertainty about the actual risk, and are given a chance to learn about the investment option. The learning is done during the "sampling stage", which precedes the final decision. During the sampling stage, individuals can experiment with the investment option: every time they press a button, they get to see a random draw from the lottery at hand. No time limit was given to this learning session, so that the number of random draws "experienced" by each participant could be anywhere between zero and infinity. As Table 6 illustrates, both the probabilities and payouts varied substantially across questions, so that a rather substantial number of clicks was needed to get a clear sense regarding the lottery's payout structure.

\section{[TABLE 6 HERE]}

Willingness to learn exhibited a truncated normal distribution when evaluated by the maximum number of clicks. Ranging from 0 to 63 clicks, the distribution of the maximum number of clicks peaked at 1 click as a significant fraction of the participants made a decision after clicking once to learn about a random outcome of the lottery. However, more than ten percent of the participants used at least 20 clicks to learn about the content of the lottery. 


\section{4. $\quad$ Results}

\subsection{Stressors and Blood Pressure Response}

The first question to address is whether the two stressors led to an increase in physical stress. To measure the physiological response to the stressors, supervisors took subjects' blood pressure at four time points: the very beginning of the study (BP1), once the first block of questions was answered and participants had settled in (BP2), directly after the stressor (BP3), and at the very end of the study (BP4). The rationale for taking two blood pressure measures at the beginning of the study was to see whether the initial setup of the study (familiarization with computer program and hooking up of physiological devices - similar to "white coat stress") was stressful in itself; as Figure 1 illustrates, this was indeed the case, with the systolic blood pressure showing a rather remarkable decline from an average value around 135 to an average of 125 within the first 15 minutes of the laboratory session. While both the systolic and the diastolic blood pressure measures stayed more or less constant at the levels observed once settled it (measure 2), subjects exposed to the cold pressure test experienced a steep increase in blood pressure. Average levels of diastolic blood pressure increased from a level around 77 to a level around 81, and average systolic blood pressures increased by about 10 points from 124 to 135 millimeters of mercury (mmHg).

Figure 1: Laboratory Stressors and Blood Pressure
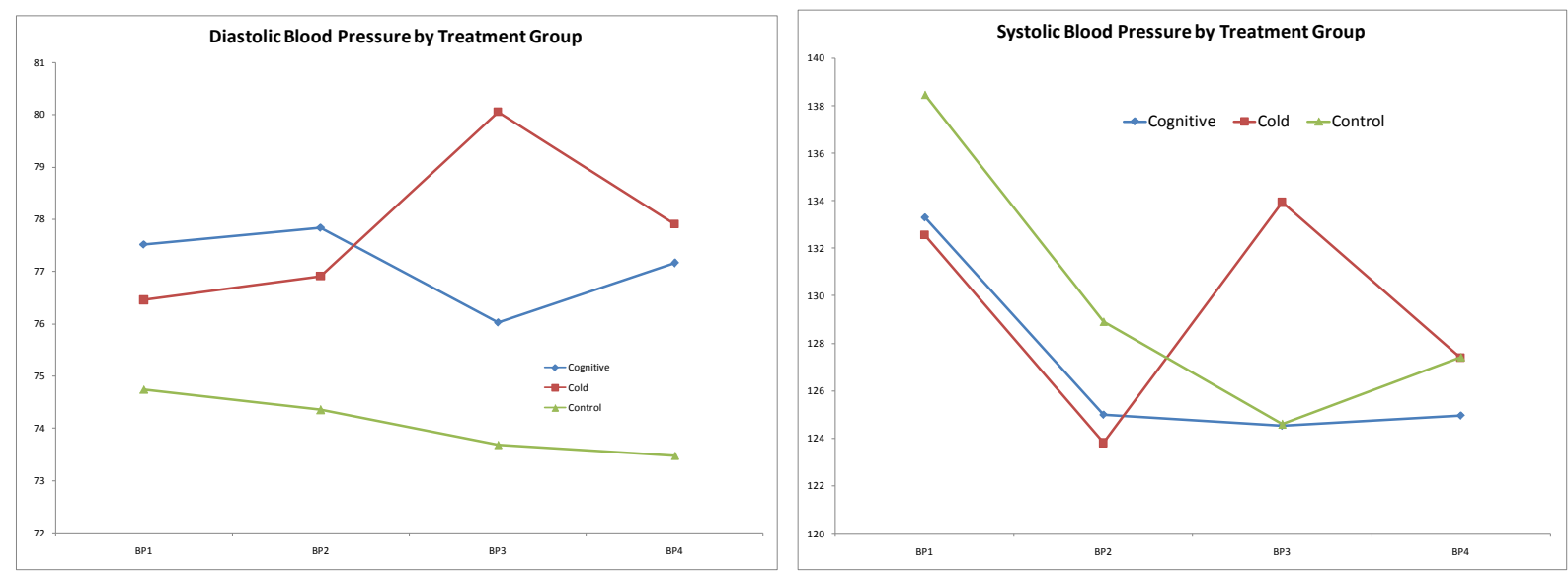

[TABLE 7 HERE] 
Table 7 presents regression results of the stressors on both blood pressure measures and shows a significant effect.

\subsection{Effects on Decision Making}

We analyze three outcome variables: the discounting rate displayed in the discounting tasks, the rate of risk aversion displayed in the Holt and Laury (2002) tasks, and the number of random draws taken from the uncertain lottery in the experience sampling tasks.

Each study participant answered one block of each task before and after the stressor in each laboratory session. Therefore we have two decision blocks for each task and study session and four decision blocks for (most) study participants. All questions answered before and after the stressor were the same for both the Day 1 and the Day 3 sessions. Table 8 shows the average response rates by question and block. While there is significant variation within each block for the time-discounting and the risk aversion tasks, the average number of samples drawn for the uncertain lotteries appears to be more or less constant across questions and days, with an average of approximately 6 draws. Given that respondents faced the same set of questions on day 1 and day 3 of the experiment, one interesting question was whether individuals would show evidence of learning, i.e. become better at answering these questions. A simple comparison of the Day 1 and Day 3 columns for the discounting and risk aversion task suggests that this was indeed the case, with individuals on average becoming more patient, but also more risk averse over time; furthermore, the average number of draws from the lottery appears to decline rather than to increase between day 1 and day 3 . 


\section{[TABLE 8 HERE]}

To investigate the effects of stress on decision-making, we estimate the following model

$$
Y_{i t}=\alpha+\beta_{1} P S+\beta_{2} C S+\delta_{t}+\delta_{i}+\varepsilon_{i t},
$$

where $y$ is the decision parameter of interest for individual $i$ in block $t$, PS is an indicator for whether the person was under physical stress when taking the decisions, CS an indicator for whether the person was under cognitive stress when taking the decision, and $\delta_{t}, \partial_{i}$ are block and individual fixed effects. The inclusion of individual fixed effects implies that estimates exclusively explore the within-subject variations in decision patterns under various stress conditions; temporal fixed effects are included to control for general learning or exhaustion effects between the various sessions.

\section{[TABLE 9 HERE]}

Table 9 shows the main results on our experimental treatment. Column 1 of Table 9 shows the result for the discounting rates computed based on the decision patterns in the time discounting tasks. Average discounting rates in the non-stressed conditions were $90 \%$ - both the cognitive and the cold stressor - appear to increase this rate by about 30 percentage points, with slightly larger effects for the cognitive stressor. Column (2) shows the results for the risk aversion parameter computed based on the risky lottery tasks. The average risk aversion parameter (rho) among non-stressed subjects was 0.34 with a large standard deviation of 1.2. The results in Table 9 suggest that both stressors increase risk aversion, but both effects are small (0.1 in absolute magnitude corresponds to about $0.25 \mathrm{SDs}$ ), and not statistically significant. Column (3) shows the results for the experience sampling task. The dependent variable in this regression is the natural log of the number of clicks, so that the estimated coefficients reflect percentage changes. The results presented suggest that both stressors reduce the willingness to learn by about 20 percent, with slightly large (but not statistically different) point estimates for the cold stressor. Results look similar when the absolute number of clicks is taken as dependent variable (not shown); the estimated 20 percent reduction corresponds to a reduction from an average of 6 clicks pre-stressor to 4.5 clicks under stress.

[TABLE 10 HERE] 
Table 10 displays the predictive effect of individual differences on choices across the three tasks. As found in Daly et al (2009) higher blood pressure predicts higher discount rates. Furthermore, higher cortisol rates predict higher discount rates. However, higher cortisol rates also predict higher levels of exploratory behaviour in the experience sampling task. Neither cortisol nor blood pressure predicts risk preferences.

\section{Discussion}

This paper demonstrates strong effects of an experimentally induced stressor on both time preferences and willingness to learn. Our effects are both statistically significant and sizable in magnitude. When exposed to a randomly assigned minor stressor, experimental respondents exhibit more present-focused preferences and also are less likely to explore available options. We do not find an effect of either cognitive or physiological stress on risk attitudes. Our results are strengthened by the use of well-known economic preference tasks that have been examined in an extensive literature, as well as well-tested psychological stress paradigms.

These results are important in providing empirical evidence and a plausible biological basis for preference reversals in key areas of economic decision-making. They are also potentially important for policy. Many real-world financial decisions arguably involve stress at the point of decision and our results clearly suggest that this may lead to fewer exploratory and less future-oriented decisions with clearly negative potential for individual and societal welfare. For example, stress-induced increases in discounting or declines in willingness to search could potentially lead to lower levels of job search leading to either prolonged unemployment or increased likelihood of accepting lower-quality positions. Recent work by Mani et al. (2013) suggests that poverty can impede cognitive function and the quality of decisions - the results presented in this study suggest that physical or cognitive stress could play an important role in this relationship.

Our results are limited to the extent that the tasks used are stylized experimental elicitations of preferences. Our results on discounting are at odds with those of Haushofer et al who do not find any effect of experimentally induced stress on time discounting. The use of different age samples is one potential explanation of the differences and future research on the life-cycle of stress reactivity on preferences would be very informative in this regard. While such tasks offer the advantage of providing data that can be quantified in meaningful economic 
magnitudes, the extent to which they are analogous to real-world financial decisions is a matter of debate. Furthermore, the extent to which experimentally induced stressors mimic the qualitative nature of stress experienced during real-world financial decisions is a question for future research.

The development of naturalistic designs to examine the role of stress in important realworld financial decisions is an important area for future research. The endogeneity of timing of stressful decisions is a clear barrier to the development of such studies and field trials that can account for this will provide an important mechanism for testing the connection between the effects of experimental and real-world stress. 


\section{References}

Ainslie, G., \& Haslam, N. Hyperbolic Discounting. In G. Loewenstein \& J. Elster, Eds., Choice Over Time. New York: Russell Sage Foundation, pp. 57-92, 1992.

Birnie, K. Noel, M., Chambers, C. T., von Baeyer, C. L., \& Fernandez, C. V. (2011). The cold pressor task: is it an ethically acceptable pain research method in children? Journal of Pediatric Psychology, 36(10), 1071-81. doi:10.1093/jpepsy/jsq092

Camerer, C.F., Lowenstein, G., \& Prelec, D. (2004). Neuroeconomics: why economics needs brains. The Scandinavian Journal of Economics, 106(3), 555-579.

Coates, J. M., \& Herbert, J. (2008). Endogenous steroids and financial risk taking on a London trading floor. Proceedings of the National Academy of Sciences of the United States of America, 105(16), 6167-72. doi:10.1073/pnas.0704025105

Dickerson, S. S., \& Kemeny, M. E. (2004). Acute stressors and cortisol responses: a theoretical integration and synthesis of laboratory research. Psychological Bulletin, 130(3), 355-91. doi:10.1037/0033-2909.130.3.355

Erev, I., et al. (2010). "A choice prediction competition: Choices from experience and from description." Journal of Behavioral Decision Making 23(1): 15-47.

Frederick, S., Loewenstein, G. \& O’Donoghue, T. (2002). Time Discounting and Time Preference: A Critical Review. Journal of Economic Literature, 40(2), 351-401.

Gronwall, D.M.A. (1977). Paced auditory serial-addition task: A measure of recovery from concussion. Perceptual and Motor Skills, 44, 367-373.

Heereman, J., \& Walla, P. (2011). Stress, uncertainty and decision confidence. Applied psychophysiology and biofeedback, 36(4), 273-9. doi:10.1007/s10484-011-9167-9 
Hertwig, R., Barron, G., Weber, E. U., \& Erev, I. (2004). Decisions from experience and the effect of rare events in risky choice. Psychological Science, 15, 534-539

Holt, C. A., K. Laury. (2002). Risk Aversion and Incentive Effects. American Economic Review, 92, 1644-1655.

Haushofer, J., Cornelisse, S., Seinstra, M., Fehrm E., Joëls, M., Kalenscher, T. (2013). No Effects of Psychosocial Stress on Intertemporal Choice. PLoS One, 8;8(11): e78597. doi: 10.1371/journal.pone.0078597.

Humstone, H. J.(1919). Memory Span Tests. Psychol. Clin., 12, 196-200.

Jensen AR, Rohwer WD (1966). The Stroop color-word test: a review. Acta psychologica. 25 (1): 36-93.

Kirby, K. N., \& Marakovic, N. N. (1996). Delay-discounting probabilistic rewards: Rates decrease as amounts increase. Psychonomic Bulletin and Review, 3,100-104.

Knapp, A. \& Clark, M.S. (1991). Some Detrimental Effects of Negative Mood on Individuals' Ability to Solve Resource Dilemmas. Personality and Social Psychology Bulletin, 17, 678-688.

Krueger, Alan B. and Mueller, A., (2010). Job search and unemployment insurance: New evidence from time use data. Journal of Public Economics, 94(3-4), 298-307.

Krueger, A., and Mueller, A., (2012). Time Use, Emotional Well-being, and Unemployment: Evidence from Longitudinal Data. American Economic Review, 102(3), 594-599.

Laibson, D.I., Repetto, A. \& Tobacman, J. (2007). Discount functions with consumption choices over the lifecycle. NBER Working Paper 13314. 
Loewenstein, G., \& Lerner, J. S. (2003). The role of affect in decision making. In R. Davidson, K. Scherer \& H. Goldsmith (Eds.), Handbook of affective science (pp. 619-642). New York: Oxford University Press.

Mani A, Mullainathan S, Shafir E, Zhao J. (2013) Poverty impedes cognitive function. Science, 341, 976-980.

McClure, S., Ericson, K.M., Laibson, D.I., Loewenstein, G. \& Cohen, J.D. (2007). Time Discounting for Primary Rewards. The Journal of Neuroscience, 27(21), 5796-5804.

McClure, S.M,. Laibson, D.I., Loewenstein, G, Cohen, J.D. (2004). Separate neural systems value immediate and delayed monetary rewards. Science, 306, 503-50.

Nater, U. M., \& Rohleder, N. (2009). Salivary alpha-amylase as a non-invasive biomarker for the sympathetic nervous system: current state of research. Psychoneuroendocrinology, 34(4), 486-96. doi:10.1016/j.psyneuen.2009.01.014

Porcelli, A. J., \& Delgado, M. R. (2009). Acute stress modulates risk taking in financial decision making. Psychological Science, 20(3), 278-83. doi:10.1111/j.1467-9280.2009.02288.x

Preston, S. D., Buchanan, T. W., Stansfield, R. B., \& Bechara, A. (2007). Effects of anticipatory stress on decision making in a gambling task. Behavioral Neuroscience, 121(2), 257-63. doi:10.1037/0735-7044.121.2.257

Reynolds, B., Ortengren, A., Richards, J.B. \& de Wit, H. (2006). Dimensions of impulsive behaviour: Personality and behavioural measures. Personality and Individual Differences, 40, 305-315. 
Richardson HL, Macey PM, Kumar R, Valladares EM, Woo MA \& RM Harper (2013). Neural and physiological responses to a cold pressor challenge in healthy adolescents. J. Neurosci. Res, 91,1618-1627.

Schroeder RW, Twumasi-Ankrah P, Baade LE, Marshall PS (2012). Reliable Digit Span: a systematic review and cross-validation study. Assessment, 19, 21-30.

Samuelson, P.A. (1937). A Note on Measurement of Utility. The Review of Economic Studies, 4(2), 155-61.

Shamosh, N. A., DeYoung, C. G., Green, A. E., Reis, D. L., Johnson, M. R., Conway, A. R. A., Engle, R.W., Braver, T.S. \& Gray, J. R. (2008). Individual differences in delay discounting: Relation to intelligence, working memory, and anterior prefrontal cortex. Psychological Science, 19, 904-911.

Shamosh, N., \& Gray, J. (2008). Delay discounting and intelligence: A meta-analysis. Intelligence, 36(4), 289-305. doi:10.1016/j.intell.2007.09.004

U.S. Census Bureau. 2011. Current population survey, annual social and economic supplement, 2010. http://www.census.gov/population/www/socdemo/age/age_sex_2010.html.

Van den Bos, R., Harteveld, M., \& Stoop, H. (2009). Stress and decision-making in humans: performance is related to cortisol reactivity, albeit differently in men and women. Psychoneuroendocrinology, 34(10), 1449-58. doi:10.1016/j.psyneuen.2009.04.016

Wirch JL, Wolfe LA, Weissgerber TL \& Davies GA. (2006). Cold pressor test protocol to evaluate cardiac autonomic function. Appl. Physiol. Nutr. Metab, 31, 235-243. 
Table 1

Descriptive Statistics - Study vs. US Population > 50 years of Age

\begin{tabular}{|c|c|c|}
\hline & Study Population & U.S. Population \\
\hline \multicolumn{3}{|l|}{ Gender } \\
\hline Male & 0.573 & 0.464 \\
\hline Female & 0.427 & 0.536 \\
\hline \multicolumn{3}{|l|}{ Race } \\
\hline African-American & 0.089 & 0.100 \\
\hline Asian-American & 0.089 & 0.039 \\
\hline White/Caucasian & 0.822 & 0.844 \\
\hline \multicolumn{3}{|l|}{ Marital Status } \\
\hline Never married & 0.411 & 0.074 \\
\hline Married & 0.173 & 0.630 \\
\hline Divorced or separated & 0.357 & 0.157 \\
\hline Widowed & 0.060 & 0.140 \\
\hline \multicolumn{3}{|l|}{ Household size } \\
\hline One person & 0.595 & 0.376 \\
\hline Two people & 0.227 & 0.456 \\
\hline Three people & 0.114 & 0.097 \\
\hline Four people & 0.022 & 0.041 \\
\hline Five or more people & 0.032 & 0.030 \\
\hline \multicolumn{3}{|l|}{ Highest level of education } \\
\hline Some high school & 0.011 & 0.144 \\
\hline High school diploma or equivalent & 0.043 & 0.337 \\
\hline Some college & 0.265 & 0.244 \\
\hline College diploma & 0.357 & 0.164 \\
\hline Graduate degree & 0.324 & 0.110 \\
\hline \multicolumn{3}{|l|}{ Employment status } \\
\hline \% working & 0.395 & 0.457 \\
\hline \multicolumn{3}{|l|}{ Income } \\
\hline Income: $\$ 0-\$ 20,000$ & 0.357 & 0.099 \\
\hline Income: $\$ 20,001$ - $\$ 75,000$ & 0.395 & 0.671 \\
\hline Income: $\$ 75,001$ - $\$ 100,000$ & 0.141 & 0.096 \\
\hline Income: $\$ 100,001$ or more & 0.065 & 0.134 \\
\hline
\end{tabular}

SOURCE: Author calculations based on US Census Bureau 2010 statistics. 
Table 2

Descriptive Statistics - Study Population

\begin{tabular}{lccccccc}
\hline & \multicolumn{2}{c}{$\begin{array}{c}\text { Control } \\
(\mathbf{N = 2 3 )}\end{array}$} & \multicolumn{2}{c}{$\begin{array}{c}\text { Cold Pressor } \\
\mathbf{( N = 8 0 )}\end{array}$} & $\begin{array}{c}\text { Cognitive Stressor } \\
(\mathbf{N = 8 4 )}\end{array}$ & F-stat \\
\hline Variable & Mean & Std.dev. & Mean & Std.dev. & Mean & Std.dev. & (pvalue) \\
Year of birth & 1949 & 9.04 & 1953 & 5.85 & 1953 & 6.08 & 0.0232 \\
Female & 0.48 & 0.51 & 0.43 & 0.50 & 0.41 & 0.50 & 0.8629 \\
High school or less & 0.17 & 0.39 & 0.04 & 0.19 & 0.04 & 0.19 & 0.0246 \\
College & 0.26 & 0.45 & 0.55 & 0.50 & 0.57 & 0.50 & 0.0244 \\
Grad school & 0.57 & 0.51 & 0.41 & 0.50 & 0.39 & 0.49 & 0.3198 \\
Single & 0.43 & 0.51 & 0.40 & 0.49 & 0.41 & 0.50 & 0.9561 \\
Married & 0.17 & 0.39 & 0.16 & 0.37 & 0.18 & 0.39 & 0.9633 \\
Separated & 0.26 & 0.45 & 0.39 & 0.49 & 0.35 & 0.48 & 0.5279 \\
Widowed & 0.13 & 0.34 & 0.05 & 0.22 & 0.05 & 0.22 & 0.2997 \\
Household size & 1.52 & 0.73 & 1.71 & 1.10 & 1.72 & 1.09 & 0.7129 \\
Number of children & 1.65 & 1.72 & 1.38 & 1.65 & 1.30 & 1.65 & 0.6742 \\
Working & 0.39 & 0.50 & 0.43 & 0.50 & 0.37 & 0.48 & 0.6764 \\
Unemployed & 0.22 & 0.42 & 0.40 & 0.49 & 0.44 & 0.50 & 0.1814 \\
Retired & 0.39 & 0.50 & 0.18 & 0.38 & 0.20 & 0.40 & 0.0687 \\
\hline
\end{tabular}


Table 3

\section{Time Discounting Choices}

\section{Round I}

\begin{tabular}{|c|c|c|c|c|c|c|c|}
\hline Question & & Option A & \multicolumn{4}{|c|}{ Option B } & Monthly interest rate \\
\hline 1 & $\$ 17$ & tonight & $\$ 42$ & in & 43 & days & $102.6 \%$ \\
\hline 2 & $\$ 42$ & tonight & $\$ 43$ & in & 35 & days & $1.0 \%$ \\
\hline 3 & $\$ 24$ & tonight & $\$ 28$ & in & 45 & days & $9.7 \%$ \\
\hline 4 & $\$ 11$ & tonight & $\$ 15$ & in & 75 & days & $17.1 \%$ \\
\hline 5 & $\$ 15$ & tonight & $\$ 18$ & in & 20 & days & $25.0 \%$ \\
\hline 6 & $\$ 34$ & tonight & $\$ 43$ & in & 35 & days & $23.0 \%$ \\
\hline 7 & $\$ 13$ & tonight & $\$ 18$ & in & 25 & days & $48.0 \%$ \\
\hline 8 & $\$ 23$ & tonight & $\$ 35$ & in & 35 & days & $47.6 \%$ \\
\hline 9 & $\$ 16$ & tonight & $\$ 28$ & in & 20 & days & $107.8 \%$ \\
\hline 10 & $\$ 8$ & tonight & $\$ 18$ & in & 10 & days & $400.0 \%$ \\
\hline 11 & $\$ 15$ & tonight & $\$ 43$ & in & 14 & days & $392.9 \%$ \\
\hline \multicolumn{8}{|c|}{ Round II } \\
\hline Question & \multicolumn{2}{|r|}{ Option A } & \multicolumn{4}{|c|}{ Option B } & Monthly interest rate \\
\hline 1 & $\$ 27$ & tonight & $\$ 28$ & in & 55 & days & $2 \%$ \\
\hline 2 & $\$ 14$ & tonight & $\$ 15$ & in & 35 & days & $10 \%$ \\
\hline 3 & $\$ 33$ & tonight & $\$ 38$ & in & 50 & days & $9 \%$ \\
\hline 4 & $\$ 24$ & tonight & $\$ 30$ & in & 50 & days & $17 \%$ \\
\hline 5 & $\$ 20$ & tonight & $\$ 33$ & in & 70 & days & $27 \%$ \\
\hline 6 & $\$ 25$ & tonight & $\$ 40$ & in & 70 & days & $26 \%$ \\
\hline 7 & $\$ 20$ & tonight & $\$ 28$ & in & 25 & days & $45 \%$ \\
\hline 8 & $\$ 8$ & tonight & $\$ 15$ & in & 35 & days & $75 \%$ \\
\hline 9 & $\$ 20$ & tonight & $\$ 35$ & in & 20 & days & $113 \%$ \\
\hline 10 & $\$ 12$ & tonight & $\$ 28$ & in & 10 & days & $388 \%$ \\
\hline
\end{tabular}




\section{Table 4: Risky Lottery Question Sequence}

Round I

\begin{tabular}{|c|c|c|c|c|c|c|c|c|c|c|c|}
\hline \multirow[b]{2}{*}{ Order } & \multirow[b]{2}{*}{ Prob 1} & \multirow[b]{2}{*}{ Prob 2} & \multicolumn{2}{|c|}{ Lottery A } & \multicolumn{2}{|c|}{ Lottery B } & \multirow[b]{2}{*}{$\Delta \mathrm{E}$} & \multirow[b]{2}{*}{$\Delta$ var } & \multirow{2}{*}{$\begin{array}{l}\Delta \mathrm{E} / \\
\Delta \mathrm{var}\end{array}$} & \multirow[b]{2}{*}{ rho } & \multirow[b]{2}{*}{ Type } \\
\hline & & & Payout 1 & Payout 2 & Payout 1 & Payout 2 & & & & & \\
\hline 1 & $90 \%$ & $10 \%$ & 5 & 7.5 & 2.5 & 12.5 & -1.8 & 8 & -0.21 & -1.54 & RL \\
\hline 2 & $60 \%$ & $40 \%$ & 20 & 30 & 10 & 50 & 2.0 & 360 & 0.01 & 0.30 & \\
\hline 3 & $10 \%$ & $90 \%$ & 20 & 30 & 10 & 50 & 17.0 & 135 & 0.13 & 2.85 & \\
\hline 4 & $70 \%$ & $30 \%$ & 5 & 7.5 & 2.5 & 12.5 & -0.3 & 20 & -0.01 & -0.15 & RL \\
\hline 5 & $30 \%$ & $70 \%$ & 20 & 30 & 10 & 50 & 11.0 & 315 & 0.03 & 1.54 & \\
\hline 6 & $10 \%$ & $90 \%$ & 5 & 7.5 & 2.5 & 12.5 & 4.3 & 8 & 0.50 & 2.85 & \\
\hline 7 & $30 \%$ & $70 \%$ & 5 & 7.5 & 2.5 & 12.5 & 2.8 & 20 & 0.14 & 1.54 & \\
\hline 8 & $90 \%$ & $10 \%$ & 20 & 30 & 10 & 50 & -7.0 & 135 & -0.05 & -1.54 & $\mathrm{RL}$ \\
\hline 9 & $70 \%$ & $30 \%$ & 20 & 30 & 10 & 50 & -1.0 & 315 & 0.00 & -0.15 & $\mathrm{RL}$ \\
\hline 10 & $60 \%$ & $40 \%$ & 5 & 7.5 & 2.5 & 12.5 & 0.5 & 23 & 0.02 & 0.30 & \\
\hline \multicolumn{12}{|c|}{ Round II } \\
\hline & & & \multicolumn{2}{|c|}{ Lottery A } & \multicolumn{2}{|c|}{ Lottery B } & & \\
\hline Order & Prob 1 & Prob 2 & Payout 1 & Payout 2 & Payout 1 & Payout 2 & $\Delta \mathrm{E}$ & $\Delta$ var & $\begin{array}{c}\Delta \mathrm{E} / \Delta \\
\mathrm{var}\end{array}$ & rho & Cat \\
\hline 1 & $70 \%$ & $30 \%$ & 20 & 30 & 10 & 50 & -1.0 & 315 & 0.00 & -0.15 & $\mathrm{RL}$ \\
\hline 2 & $30 \%$ & $70 \%$ & 5 & 7.5 & 2.5 & 12.5 & 2.8 & 20 & 0.14 & 1.54 & \\
\hline 3 & $60 \%$ & $40 \%$ & 20 & 30 & 10 & 50 & 2.0 & 360 & 0.01 & 0.30 & \\
\hline 4 & $70 \%$ & $30 \%$ & 5 & 7.5 & 2.5 & 12.5 & -0.3 & 20 & -0.01 & -0.15 & RL \\
\hline 5 & $30 \%$ & $70 \%$ & 20 & 30 & 10 & 50 & 11.0 & 315 & 0.03 & 1.54 & \\
\hline 6 & $90 \%$ & $10 \%$ & 5 & 7.5 & 2.5 & 12.5 & -1.8 & 8 & -0.21 & -1.54 & $\mathrm{RL}$ \\
\hline 7 & $10 \%$ & $90 \%$ & 5 & 7.5 & 2.5 & 12.5 & 4.3 & 8 & 0.50 & 2.85 & \\
\hline 8 & $60 \%$ & $40 \%$ & 5 & 7.5 & 2.5 & 12.5 & 0.5 & 23 & 0.02 & 0.30 & \\
\hline 9 & $10 \%$ & $90 \%$ & 20 & 30 & 10 & 50 & 17.0 & 135 & 0.13 & 2.85 & \\
\hline 10 & $90 \%$ & $10 \%$ & 20 & 30 & 10 & 50 & -7.0 & 135 & -0.05 & -1.54 & $\mathrm{RL}$ \\
\hline
\end{tabular}

Notes: RL stands for risk-loving preferences; rho is the CRRA rate to make a rational agent indifferent. 


\section{Table 5}

\section{Risky Lottery Choices Ranked by Differences in Expected Value \& Actual Decisions}

\begin{tabular}{ccccc}
\hline Question & Option A & Option B & $\Delta$ E & $\begin{array}{c}\text { Fraction } \\
\text { Choosing } \\
\text { A }\end{array}$ \\
\hline 3 & $90 \%$ of $\$ 20$ and $10 \%$ of $\$ 30$ & $90 \%$ of $\$ 10$ and $10 \%$ of $\$ 50$ & 17 & 0.808 \\
5 & $90 \%$ of $\$ 5$ and $10 \%$ of $\$ 7.5$ & $90 \%$ of $\$ 2.5$ and $10 \%$ of $\$ 12.5$ & 11 & 0.845 \\
6 & $70 \%$ of $\$ 20$ and $30 \%$ of $\$ 30$ & $70 \%$ of $\$ 10$ and $30 \%$ of $\$ 50$ & 4.3 & 0.738 \\
7 & $70 \%$ of $\$ 5$ and $30 \%$ of $\$ 7.5$ & $70 \%$ of $\$ 2.5$ and $30 \%$ of $\$ 12.5$ & 2.8 & 0.658 \\
2 & $60 \%$ of $\$ 5$ and $40 \%$ of $\$ 7.5$ & $60 \%$ of $\$ 2.5$ and $40 \%$ of $\$ 12.5$ & 2 & 0.578 \\
10 & $60 \%$ of $\$ 20$ and $40 \%$ of $\$ 30$ & $60 \%$ of $\$ 10$ and $40 \%$ of $\$ 50$ & 0.5 & 0.481 \\
4 & $30 \%$ of $\$ 5$ and $70 \%$ of $\$ 7.5$ & $30 \%$ of $\$ 2.5$ and $70 \%$ of $\$ 12.5$ & -0.3 & 0.155 \\
9 & $10 \%$ of $\$ 5$ and $90 \%$ of $\$ 7.5$ & $10 \%$ of $\$ 2.5$ and $90 \%$ of $\$ 12.5$ & -1 & 0.139 \\
1 & $30 \%$ of $\$ 20$ and $70 \%$ of $\$ 30$ & $30 \%$ of $\$ 10$ and $70 \%$ of $\$ 50$ & -1.8 & -7 \\
8 & $10 \%$ of $\$ 20$ and $90 \%$ of $\$ 30$ & $10 \%$ of $\$ 10$ and $90 \%$ of 50 & & 0.080 \\
\hline
\end{tabular}


Table 6

Experience Sampling - Willingness to Learn Task

\begin{tabular}{|c|c|c|c|c|c|c|c|c|c|c|}
\hline \multirow{2}{*}{$\begin{array}{l}\text { Round I } \\
\text { Question }\end{array}$} & \multicolumn{2}{|c|}{ Option A } & \multicolumn{4}{|c|}{ Option B } & \multicolumn{4}{|c|}{ Comparison } \\
\hline & Payout & Prob & P1 & P2 & $\mathrm{R} 1$ & R2 & $E(A)$ & $E(B)$ & $\Delta \mathrm{E}$ & Cat \\
\hline 1 & 5 & $100 \%$ & 0.8 & 0.2 & 2.5 & 25 & 5 & 7.0 & 2.0 & \\
\hline 2 & 20 & $100 \%$ & 0.8 & 0.2 & 22.5 & 2.5 & 20 & 18.5 & -1.5 & RL \\
\hline 3 & 5 & $100 \%$ & 0.6 & 0.4 & 5 & 10 & 5 & 7.0 & 2.0 & SDA \\
\hline 4 & 20 & $100 \%$ & 0.5 & 0.5 & 30 & 5 & 20 & 17.5 & -2.5 & $\mathrm{RL}$ \\
\hline 5 & 5 & $100 \%$ & 0.3 & 0.7 & 2.5 & 25 & 5 & 18.3 & 13.3 & \\
\hline 6 & 20 & $100 \%$ & 0.1 & 0.9 & 22.5 & 5 & 20 & 6.8 & -13.3 & RL \\
\hline Round II & \multicolumn{2}{|c|}{ Option A } & \multicolumn{4}{|c|}{ Option B } & \multicolumn{4}{|c|}{ Comparison } \\
\hline Question & Payout & Prob & P1 & $\mathrm{P} 2$ & $\mathrm{R} 1$ & $\mathrm{R} 2$ & $E(A)$ & $E(B)$ & $\Delta \mathrm{E}$ & Cat \\
\hline 1 & 20 & $100 \%$ & 0.5 & 0.5 & 30 & 5 & 20 & 17.5 & -2.5 & $\mathrm{RL}$ \\
\hline 2 & 5 & $100 \%$ & 0.3 & 0.7 & 2.5 & 25 & 5 & 18.3 & 13.3 & \\
\hline 3 & 20 & $100 \%$ & 0.1 & 0.9 & 22.5 & 5 & 20 & 6.8 & -13.3 & $\mathrm{RL}$ \\
\hline 4 & 5 & $100 \%$ & 0.6 & 0.4 & 5 & 10 & 5 & 7.0 & 2.0 & SDA \\
\hline 5 & 20 & $100 \%$ & 0.8 & 0.2 & 22.5 & 2.5 & 20 & 18.5 & -1.5 & $\mathrm{RL}$ \\
\hline 6 & 5 & $100 \%$ & 0.8 & 0.2 & 2.5 & 25 & 5 & 7.0 & 2.0 & \\
\hline
\end{tabular}

Notes: RL stands for risk loving preferences. SDA marks choices where the safe option A is strategically dominated by B. 
Table 7

Effect of Experiment on Physiological Outcomes

\begin{tabular}{lccc}
\hline VARIABLES & $\begin{array}{c}(1) \\
\text { Systolic blood pressure }\end{array}$ & $\begin{array}{c}(2) \\
\text { Diastolic blood } \\
\text { pressure }\end{array}$ & $\begin{array}{c}(3) \\
\text { Cortisol }\end{array}$ \\
\hline Cold & $10.83^{* * *}$ & 1.872 & -0.0410 \\
Cognitive & $(1.961)$ & $(1.429)$ & $(0.0325)$ \\
& 1.755 & -2.045 & 0.0590 \\
Post & $(1.859)$ & $(1.343)$ & $(0.0503)$ \\
Constant & -1.735 & 0.614 & -0.00777 \\
& $(1.542)$ & $(1.123)$ & $0.0212)$ \\
Observations & $124.9 * * *$ & $77.00^{* * *}$ & $(0.00908)$ \\
R-squared & $(0.632)$ & $(0.492)$ & 347 \\
\hline
\end{tabular}

All specifications include subject fixed effects. Each observation corresponds to a "pre" or a "post" stressor block of a single laboratory session. The total number of study participants was 97 with a total number of 186 sessions.

Robust standard errors in parentheses are clustered at the subject level.

*** $\mathrm{p}<0.01,{ }^{* *} \mathrm{p}<0.05, * \mathrm{p}<0.1$ 
Table 8

\section{Average Responses by Session}

\begin{tabular}{|c|c|c|c|c|c|c|}
\hline \multirow[t]{2}{*}{ Question } & \multicolumn{2}{|c|}{$\begin{array}{c}\text { Fraction Accepting } \\
\text { Delay }\end{array}$} & \multicolumn{2}{|c|}{$\begin{array}{c}\text { Fraction taking risky } \\
\text { option B }\end{array}$} & \multicolumn{2}{|c|}{$\begin{array}{c}\text { Average number of } \\
\text { samples drawn }\end{array}$} \\
\hline & Day 1 & Day 3 & Day 1 & Day 3 & Day 1 & Day 3 \\
\hline Pre stressor 1 & 0.76 & 0.86 & 0.20 & 0.11 & 5.54 & 5.23 \\
\hline Pre stressor 2 & 0.08 & 0.07 & 0.58 & 0.46 & 5.27 & 4.49 \\
\hline Pre stressor 3 & 0.16 & 0.17 & 0.92 & 0.92 & 6.07 & 4.73 \\
\hline Pre stressor 4 & 0.13 & 0.22 & 0.42 & 0.26 & 6.40 & 6.35 \\
\hline Pre stressor 5 & 0.27 & 0.34 & 0.89 & 0.83 & 6.85 & 6.34 \\
\hline Pre stressor 6 & 0.52 & 0.53 & 0.85 & 0.84 & 6.04 & 5.79 \\
\hline Pre stressor 7 & 0.46 & 0.49 & 0.83 & 0.78 & & \\
\hline Pre stressor 8 & 0.59 & 0.64 & 0.25 & 0.13 & & \\
\hline Pre stressor 9 & 0.81 & 0.86 & 0.29 & 0.23 & & \\
\hline Pre stressor 10 & 0.87 & 0.92 & 0.47 & 0.37 & & \\
\hline Pre stressor 11 & 0.86 & 0.92 & & & & \\
\hline Post stressor 1 & 0.05 & 0.03 & 0.29 & 0.24 & 7.36 & 6.51 \\
\hline Post stressor 2 & 0.06 & 0.07 & 0.81 & 0.77 & 6.55 & 6.79 \\
\hline Post stressor 3 & 0.16 & 0.23 & 0.56 & 0.49 & 5.89 & 5.77 \\
\hline Post stressor 4 & 0.20 & 0.24 & 0.37 & 0.23 & 5.29 & 5.65 \\
\hline Post stressor 5 & 0.36 & 0.41 & 0.82 & 0.83 & 5.17 & 4.88 \\
\hline Post stressor 6 & 0.54 & 0.52 & 0.14 & 0.12 & 5.29 & 4.99 \\
\hline Post stressor 7 & 0.41 & 0.53 & 0.91 & 0.86 & & \\
\hline Post stressor 8 & 0.68 & 0.71 & 0.48 & 0.40 & & \\
\hline Post stressor 9 & 0.76 & 0.79 & 0.88 & 0.90 & & \\
\hline Post stressor 10 & 0.89 & 0.95 & 0.17 & 0.13 & & \\
\hline
\end{tabular}


Table 9:

Main results

\begin{tabular}{lccc}
\hline VARIABLES & $\begin{array}{c}\text { Discounting } \\
\text { rate }^{\mathbf{a})}\end{array}$ & $\begin{array}{c}\text { Rate of risk } \\
\text { aversion }^{\mathbf{b}}\end{array}$ & $\begin{array}{c}\text { Experience } \\
\text { sampling }^{\mathbf{c}}\end{array}$ \\
\hline Cold & $(1)$ & $(2)$ & $(3)$ \\
Cognitive & $0.272^{*}$ & 0.120 & $-0.206^{* *}$ \\
Post & $(0.151)$ & $(0.297)$ & $(0.103)$ \\
Constant & $0.346^{* *}$ & 0.325 & $-0.187^{*}$ \\
& $(0.149)$ & $(0.303)$ & $(0.105)$ \\
Observations & $-0.243^{*}$ & -0.229 & 0.141 \\
R-squared & $(0.134)$ & $(0.268)$ & $(0.101)$ \\
\hline
\end{tabular}

Notes: ${ }^{\text {a) }}$ Dependent variable is the discounting rate computed based on the time discounting choices shown in Table 3. ${ }^{\text {b) }}$ Dependent variable is the rate of risk aversion computed based on the risky lottery options in Table 4. ${ }^{c)}$ Dependent variable is the natural logarithm of the average number of random draws taken by the subject for the experience learning tasks outlined in Table 6. All specifications include subject fixed effects. Each observation corresponds to a "pre" or a "post" stressor block of a single laboratory session. The total number of study participants was 97 with a total number of 186 sessions. Robust standard errors in parentheses are clustered at the subject level. ${ }^{* * *} \mathrm{p}<0.01,{ }^{* *} \mathrm{p}<0.05,{ }^{*} \mathrm{p}<0.1$ 
Table 10: Individual Differences in Economic Preferences

\begin{tabular}{|c|c|c|c|}
\hline & $\begin{array}{c}\text { Discounting } \\
\text { rate }^{\text {a) }}\end{array}$ & $\begin{array}{c}\text { Rate of risk } \\
\text { aversion }^{\text {b) }}\end{array}$ & $\begin{array}{c}\text { Experience } \\
\text { samplingc) }\end{array}$ \\
\hline & $(1)$ & $(2)$ & (3) \\
\hline Systolic blood pressure & $\begin{array}{l}-0.00683 \\
(0.00593)\end{array}$ & $\begin{array}{l}0.000663 \\
(0.00767)\end{array}$ & $\begin{array}{l}-0.00607 \\
(0.00393)\end{array}$ \\
\hline Diastolic blood pressure & $\begin{array}{c}0.0230^{* * *} \\
(0.00795)\end{array}$ & $\begin{array}{c}-0.00360 \\
(0.0110)\end{array}$ & $\begin{array}{c}0.00169 \\
(0.00669)\end{array}$ \\
\hline Cortisol & $\begin{array}{c}0.279 * * \\
(0.118)\end{array}$ & $\begin{array}{l}-0.0890 \\
(0.121)\end{array}$ & $\begin{array}{l}0.319 * * * \\
(0.0794)\end{array}$ \\
\hline Age & $\begin{array}{l}-0.159 \\
(0.165)\end{array}$ & $\begin{array}{c}0.205 \\
(0.214)\end{array}$ & $\begin{array}{l}0.0451 \\
(0.189)\end{array}$ \\
\hline Age squared & $\begin{array}{c}0.00127 \\
(0.00128)\end{array}$ & $\begin{array}{l}-0.00165 \\
(0.00167)\end{array}$ & $\begin{array}{l}-0.000253 \\
(0.00152)\end{array}$ \\
\hline Female & $\begin{array}{l}-0.283 \\
(0.178)\end{array}$ & $\begin{array}{l}-0.229 \\
(0.234)\end{array}$ & $\begin{array}{l}0.0156 \\
(0.167)\end{array}$ \\
\hline High school or less & $\begin{array}{c}2.157 * * * \\
(0.620)\end{array}$ & $\begin{array}{l}-0.541 \\
(0.545)\end{array}$ & $\begin{array}{c}-0.894 * * * \\
(0.303)\end{array}$ \\
\hline College & $\begin{array}{c}0.292 \\
(0.179)\end{array}$ & $\begin{array}{l}0.0376 \\
(0.211)\end{array}$ & $\begin{array}{c}-0.408^{* *} \\
(0.189)\end{array}$ \\
\hline Single & $\begin{array}{l}0.0349 \\
(0.306)\end{array}$ & $\begin{array}{l}0.0542 \\
(0.391)\end{array}$ & $\begin{array}{l}-0.0293 \\
(0.322)\end{array}$ \\
\hline Married & $\begin{array}{l}0.508^{*} \\
(0.280)\end{array}$ & $\begin{array}{c}0.296 \\
(0.357)\end{array}$ & $\begin{array}{l}-0.0516 \\
(0.395)\end{array}$ \\
\hline Separated & $\begin{array}{c}0.847 * * * \\
(0.299)\end{array}$ & $\begin{array}{c}0.343 \\
(0.338)\end{array}$ & $\begin{array}{l}-0.363 \\
(0.319)\end{array}$ \\
\hline Own house & $\begin{array}{l}-0.0568 \\
(0.0574)\end{array}$ & $\begin{array}{c}0.0638 \\
(0.0776)\end{array}$ & $\begin{array}{l}0.00795 \\
(0.0821)\end{array}$ \\
\hline Children & $\begin{array}{c}0.0259 \\
(0.0616)\end{array}$ & $\begin{array}{l}-0.0253 \\
(0.0783)\end{array}$ & $\begin{array}{c}0.0551 \\
(0.0588)\end{array}$ \\
\hline Working & $\begin{array}{c}0.256 \\
(0.278)\end{array}$ & $\begin{array}{c}0.197 \\
(0.351)\end{array}$ & $\begin{array}{c}0.299 \\
(0.224)\end{array}$ \\
\hline Unemployed & $\begin{array}{c}0.378 \\
(0.268)\end{array}$ & $\begin{array}{l}0.0900 \\
(0.375)\end{array}$ & $\begin{array}{c}0.305 \\
(0.228)\end{array}$ \\
\hline Income group 2 & $\begin{array}{c}0.259 \\
(0.251)\end{array}$ & $\begin{array}{l}-0.317 \\
(0.266)\end{array}$ & $\begin{array}{l}0.0550 \\
(0.175)\end{array}$ \\
\hline Income group 3 & $\begin{array}{l}-0.109 \\
(0.296)\end{array}$ & $\begin{array}{l}0.0238 \\
(0.277)\end{array}$ & $\begin{array}{l}0.372 * \\
(0.204)\end{array}$ \\
\hline Income group 4 & $\begin{array}{l}-0.120 \\
(0.236)\end{array}$ & $\begin{array}{l}-0.194 \\
(0.312)\end{array}$ & $\begin{array}{l}-0.0893 \\
(0.290)\end{array}$ \\
\hline Income group 5 & $\begin{array}{l}-0.0166 \\
(0.276)\end{array}$ & $\begin{array}{l}-0.526 \\
(0.387)\end{array}$ & $\begin{array}{l}0.0278 \\
(0.384)\end{array}$ \\
\hline Income group 6 & $\begin{array}{l}-0.177 \\
(0.321)\end{array}$ & $\begin{array}{l}-0.572 * \\
(0.302)\end{array}$ & $\begin{array}{l}0.519^{*} \\
(0.277)\end{array}$ \\
\hline Constant & $\begin{array}{l}4.095 \\
(5.264)\end{array}$ & $\begin{array}{l}-5.854 \\
(6.904)\end{array}$ & $\begin{array}{c}0.575 \\
(5.910)\end{array}$ \\
\hline Observations & 339 & 339 & 339 \\
\hline R-squared & 0.336 & 0.065 & 0.227 \\
\hline
\end{tabular}


Notes: ${ }^{\text {a) }}$ Dependent variable is the discounting rate computed based on the time discounting choices shown in Table 3. ${ }^{\text {b) }}$ Dependent variable is the rate of risk aversion computed based on the risky lottery options in Table 4. ${ }^{c)}$ Dependent variable is the natural logarithm of the average number of random draws taken by the subject for the experience learning tasks outlined in Table 6. All specifications include subject fixed effects. Each observation corresponds to a "pre" or a "post" stressor block of a single laboratory session. The total number of study

participants was 97 with a total number of 186 sessions. Robust standard errors in parentheses are clustered at the subject level. ${ }^{* * *} \mathrm{p}<0.01,{ }^{* *} \mathrm{p}<0.05,{ }^{*} \mathrm{p}<0.1$ 
Appendix 1: Picture of Cold Pressor Task Equipment

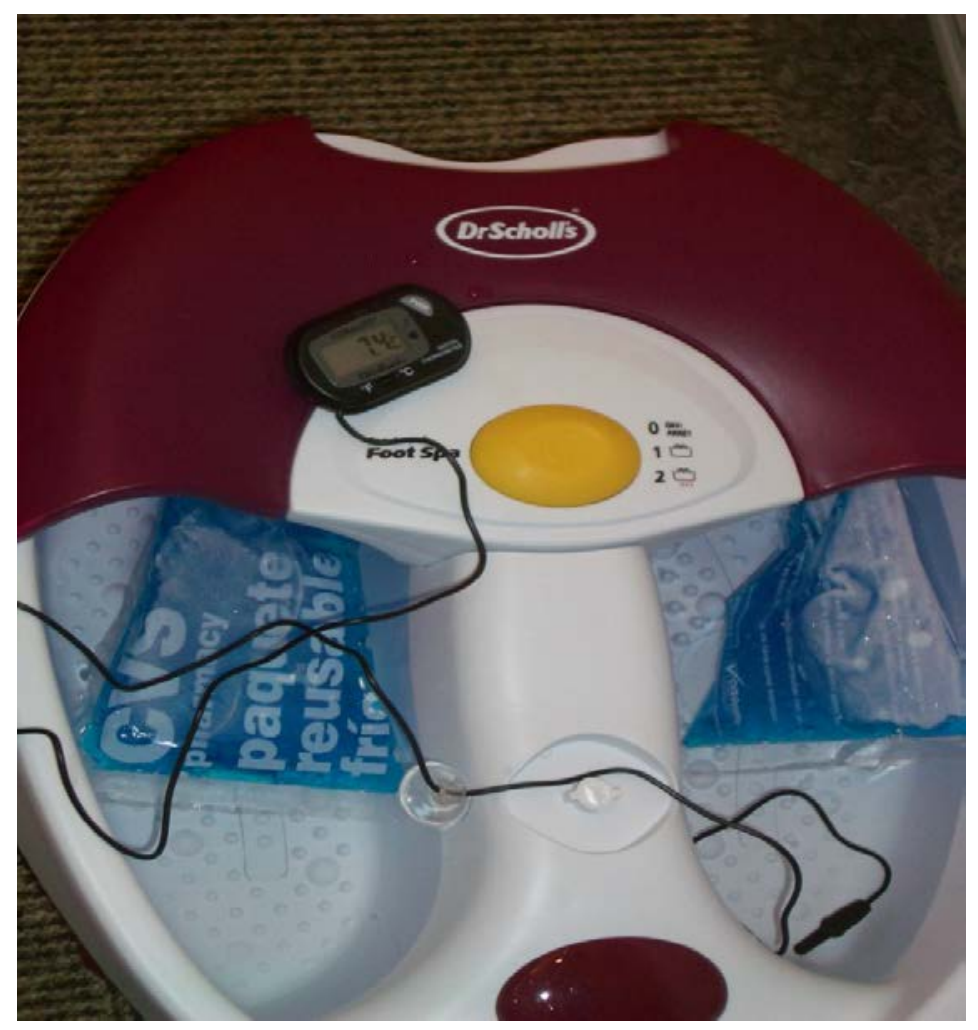




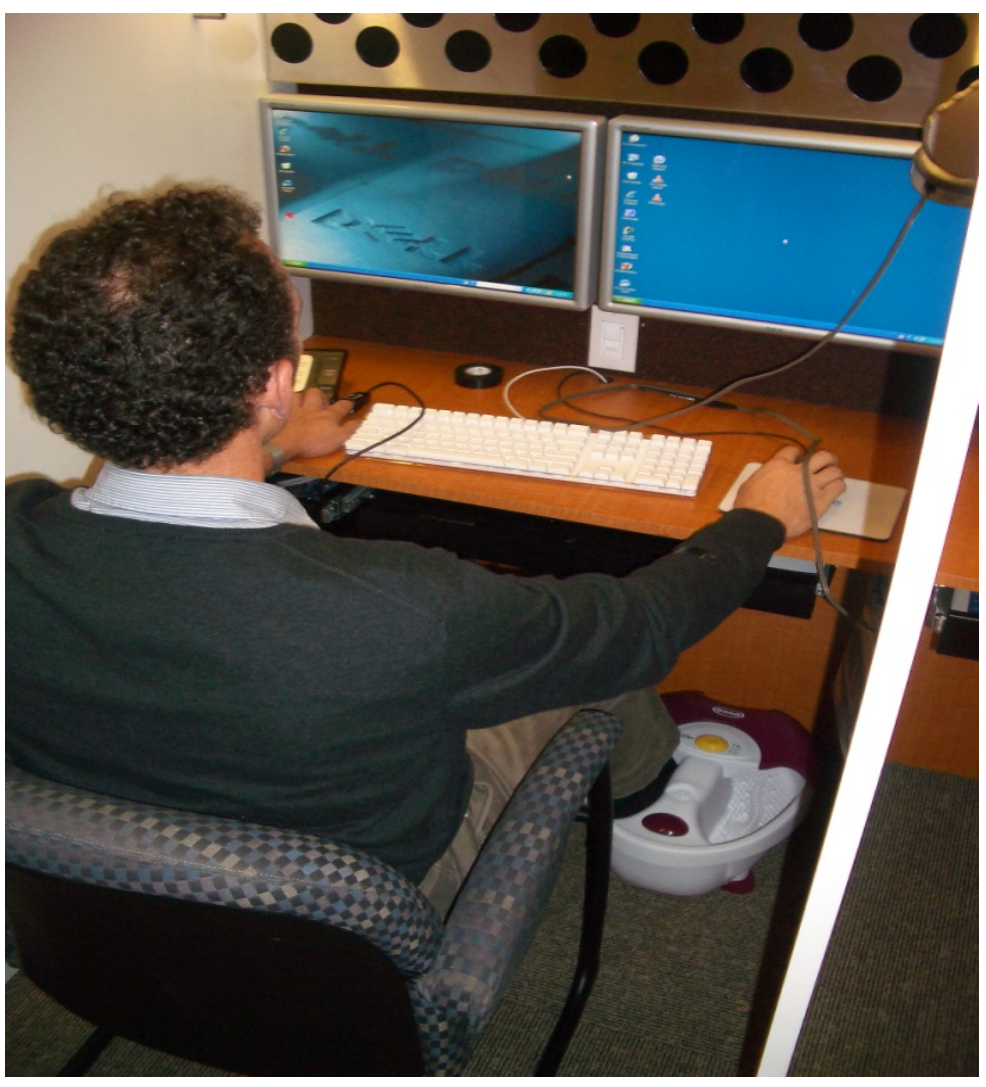

